\title{
Perancangan Aplikasi Mobile Zakat dan Infaq Berbasis Android Pada Baznas Kabupaten Tangerang
}

\author{
Imron*, Nurul Azizah, M. Sinta Nurhayati, Bambang Wijonarko \\ Universitas Bina Sarana Informatika \\ Jl Kramat Raya No. 98, Jakarta Pusat, 10420 \\ *Correspondence email: imron.imr@bsi.ac.id, nurul.azh@gmail.com, m.sinta.stn@bsi.ac.id, bambang.bwo@bsi.ac.id
}

\begin{abstract}
Abstrak. Ilmu Pengetahuan dan Teknologi dapat dimanfaatkan dalam peningkatkan kinerja pada suatu organisasi atau perusahaan. Pada masa Pandemi COVID 19, BAZNAS Kabupaten Tangerang terdorong untuk menciptakan sebuah media sebagai fasilitas untuk para dermawan dalam menyampaikan zakat dan Infaknya, dikarenakan banyak keterbatasan untuk dapat dilakukan secara langsung seperti sebelumnya. Sebuah Aplikasi menerimaan dan penyaluran zakat melalui perangkat gawai berbasis android dalam genggaman adalah solusi dari permasalahan yang dapat membantu BAZNAS Kabupaten Tangerang untuk dapat tetap menjalankan aktivitasnya. Hasil penelitian ini adalah merancang dan membangun aplikasi berbasis android pada BAZNAS Kabupaten Tangerang yang diharapkan akan mampu melayani masyarakat, menyimpan dan berbagi informasi kepada masyarakat. Didukung dengan adanya artikel, berita, dokumen Informasi, dan forum diskusi sebagai wadahnya agar meningkatkan kepercayaan dan menumbuhkan nilai-nilai kepercayaan serta keagamaan pada masyarakat.
\end{abstract}

Kata kunci: BAZNAS; zakat berbasis android; aplikasi zakat; kabupaten tangerang; infak.

Abstract. Science and Technology can be utilized in improving performance in an organization or company. During the COVID 19 Pandemic, BAZNAS Kabupaten Tangerang was encouraged to create a media as a facility for philanthropists in delivering zakat and infaknya, due to many limitations to be done directly as before. An application to receive and distribute zakat through android-based devices in the palm of the hand is the solution of the problem that can help BAZNAS Kabupaten Tangerang to be able to continue carrying out its activities. The result of this research is designing and building android-based applications in BAZNAS kabupaten Tangerang that are expected to be able to serve the community, store and share information to the community. Supported by articles, news, information documents, and discussion forums as a forum to increase trust and foster religious and religious values in the community.

Keywords: BAZNAS; android-based zakat; zakat application; Tangerang Kabupaten; infak..

\section{PENDAHULUAN}

Revolusi digital menjadikan Indonesia sebagai salah satu negara dengan pemakai smartphone terbanyak di dunia. Indonesia berada di urutan keenam setelah Amerika Serikat, Republik Rakyat Tiongkok, India, Brasil, dan Jepang. Tahun 2018 diprediksi pemakai smartphone di Indonesia mencapai 100 juta orang atau $40 \%$ dari total penduduk sebesar 250 juta jiwa. Menurut organisasi analis konten asal Virginia, Media Research Center (MRC), semakin maju sebuah negara, semakin besar persentase warganya yang memakai smartphone. Maka di kawasan Asia, Singapura menjadi negara dengan persentase terbesar, yakni Singapura $88 \%$, disusul Kore 83\%, Hongkong 79\%, Taiwan 78\%, Jepang 54\%, dan India 33\%. (Selpi Hasanah, 2018)

Badan Amil Zakat Nasional (BAZNAS) merupakan badan resmi dan satu-satunya yang dibentuk oleh pemerintah berdasarkan Keputusan Presiden RI No. 8 Tahun 2001 yang memiliki tugas dan fungsi menghimpun dan menyalurkan zakat, infaq, dan sedekah (ZIS) pada tingkat nasional.

Lahirnya Undang-Undang Nomor 23 tahun 2011 tentang pengelolaan Zakat semakin mengukuhkan peran BAZNAS sebagai lembaga yang berwenang melakukan pengelolaan zakat secara nasional.
Knowledge Management System (KMS) dapat meningkatkan pengetahuan dan kemampuan karyawan perusahaan serta dapat mengungguli perusahaan lain dalam memberikan pelayanan kepada pelanggan, dengan memanfaatkan fitur kritik dan saran, konsultasi, dan forum dimana fitur-fitur tersebut merupakan media untuk sharing knowledge antar karyawan (Alinto et al., 2014). Knowledge Manajemen System dengan Teknologi Cloud Computing dapat diterapkan untuk masalah dimana karyawan sering keluar masuk, yang menyebabkan hilangnya knowledge perusahaan bersamaan dengan keluarnya karyawan tersebut (Lusa \& Haris, 2016), Knowledge dapat dimanfaatkan dalam peningkatkan kinerja yang ada pada satu organisasi atau perusahaan, begitupun pada BAZNAS Kabupaten Tangerang, pengetahuan menjadi salah satu alat dalam pengembangan peningkatan kepercayaan masyarakat terhadap BAZNAS

Knowledge pada setiap orang sangat bervariasi dan berbagai jenis, baik dari segi tacit knowledge ataupun explicit knowledge. Tacit knowledge yang didapat dari pengalaman yang telah didapat oleh pegawai BAZNAS maupun masyarakat dan juga explicit knowledge yang didapat dari berbagai sumber yang ada, hanya menjadi pengetahuan untuk dirinya sendiri, 
sehingga proses sosialisasi untuk meningkatkan pengetahuan yang terjadi pada BAZNAS Kabupaten Tangerang masih belum berjalan dengan baik, karena tidak ada proses pengumpulan pengetahuan baru yang didapat dan proses pertukaran pengetahuan antar masyarakat yang masih bersifat manual menjadikan susahnya mendapat pengetahuan yang terpercaya, dan kurangnya pengetahuan serta kepercayaan masyarakat terhadap BAZNAS, ini mengakibatkan proses penghimpunan dana Zakat, Infaq, Shodaqoh (ZIS) tidak berjalan secara optimal.

Dalam proses menerima, mengelola dan menyalurkan zakat, infaq, dan sadaqah atau biasa disebut ZIS, Kabupaten Tangerang memiliki BAZNAS dan juga UPZ (Unit Pengelola Zakat) yang berjumlah 29 dan tersebar di tiap-tiap Kecamatan se-Kabupaten Tangerang.

ZIS yang ada di Kabupaten Tangerang semakin meningkat, akan tetapi nilai tersebut masih jauh dari hasil yang diharapkan jika melihat dari potensi zakat yang ada di Kabupaten Tangerang setiap tahunnya, yang dapat mencapai sekitar Rp. 20 miliar rupiah, sedangkan yang terealisasikan hanya 3 miliar.

Dari hasil observasi melalui KESRA Sekretariat Daerah Kabupaten Tangerang sebagai lemabaga Pemerintah yang membidangi keagamaan, "Pemerintah Daerah dalam upaya optimalisasi pengumpulan zakat, infaq dan sodaqoh melalui penyuluhan-penyuluhan kepada aparat Pemerintah maupun pengusaha sebagai muzaki bahkan telah mengeluarkan instruksi kepada aparat dan pejabat pemerintah untuk membayar zakat melalui BAZNAS Kabupaten Tangerang. Disamping itu Pemerintah Daerah telah menjadikan presentase kenaikan hasil penghimpunan zakat sebagai formulasi dari tumbuhnya nilai-nilai keagamaan dalam kehidupan bermasyarakat sebagai Indikator Kinerja Utama (IKU) Pemerintah Kabupaten Tangerang yang ditetapkan dengan Peraturan Bupati Tangerang Nomor 28 Tahun 2016 Tentang Penetapan Indikator Kinerja Utama Tahun 2013 - 2018 di lingkungan Pemerintah Kabupaten Tangerang".

BAZNAS sendiri telah melakukan beberapa kegiatan-kegiatan dalam proses peningkatan penghimpunan zakat. Langkah awal dari BAZNAS adalah meningkatkan kepercayaan kepada muzaki yang mana fakto pendukung kesuksesan suatu lembaga amil zakat adalah meningkatkan kepercayaan muzaki dalam menyalurkan wajib zakatnya kepada lembaga amil zakat.

Dalam hal ini knowledge management system dapat berfungsi dalam membantu BAZNAS dalam mengumpulkan dan mendistribusikan pengetahuan yang dimiliki BAZNAS dalam upaya peningkatan kepercayaan masyarakat terhadap BAZNAS. Jika pengetahuan akan zakat dan juga BAZNAS ini telah dapat disalurkan dengan baik, setidaknya akan membantu menumbuhkan nilai-nilai keagamaan pada masyarakat Kabupaten Tangerang dan juga akan menumbuhkan rasa kepercayaan masyarakat akan kinerja BAZNAS dalam mengelola dana ZIS yang telah terkumpul.

Dari permasalahan tersebut diatas, maka dengan ini penulis bermaksud melakukan penelitian di BAZNAS Kabupaten Tangerang dan merancang Knowledge management system untuk dapat membantu meningkatkan pendapatan zakat yang ada pada BAZNAS Kabupaten Tangerang dengan cara peningkatan pengetahuan masyarakat luas secara menyeluruh..

\section{METODE}

\section{Konsep Dasar Sistem \\ Aplikasi Mobile}

Aplikasi Mobile berasal dari dua kata, yaitu aplikasi dan mobile. Secara istilah, aplikasi adalah program siap pakai yang dibuat untuk melaksanakan suatu fungsi untuk pengguna atau aplikasi yang lain sedangkan mobile adalah perpindahan dari suatu tempat ke tempat yang lain. Secara lebih lengkap, aplikasi mobile adalah program siap pakai yang melaksanakan fungsi tertentu yang dipasang pada perangkat mobile. (Siregar, Mukmin 2016)

Menurut Wikipedia, pengertian aplikasi adalah program yang digunakan orang untuk melakukan sesuatu pada sistem komputer. Mobile dapat diartikan sebagai perpindahan yang mudah dari suatu tempat ke tempat yang lain, misalnya telepon mobile berarti bahwa terminal telepon yang dapat berpindah dengan mudah dari satu tempat ke tempat yang lain tanpa terjadi pemutusan atau terputusnya komunikasi. Sistem aplikasi mobile merupakan aplikasi yang dapat digunakan walaupun pengguna berpindah dengan mudah dari satu tempat ketempat lain tanpa terjadi pemutusan atau terputusnya komunikasi. Aplikasi ini dapat diakses melalui perangkat nirkabel seperti pager, seperti telepon seluler dan PDA. Adapun karakteristik perangkat mobile.

\section{Android}

Android adalah software platform yang open source untuk mobile device. Android berisi sistem operasi, middleware dan aplikasi-aplikasi dasar. Basis OS android adalah kernel linux 2.6 yang telah dimodifikasi untuk mobile device. (Hidayah, 2017)

Sebuah sistem operasi pada handphone yang bersifat terbuka dan berbasis pada sistem operasi Linux. Android bisa digunakan oleh setiap orang yang ingin menggunakannya pada perangkat mereka. Android menyediakan platform terbuka bagi para pengembang untuk menciptakan aplikasi mereka sendiri yang akan digunaka untuk bermacam peranti bergerak.

\section{Knowledge Management}

Secara umum pengertian knowledge adalah berbagai gejala yang ditemui dan diperoleh manusia 
melalui pengamatan akal. Pengetahuan muncul ketika seseorang menggunakan akal budinya untuk mengenali benda atau kejadian tertentu yang belum dilihat atau dirasakan sebelumnya. Pengetahuan adalah hasil pengindraan manusia atau hasil tahu seseorang terhadap objek melalui indra yang dimilikinya (mata, hidung, telinga dan sebagainya). Dengan sendirinya pada waktu pengindraan sampai menghasilkan pengetahuan tersebut sangat dipengaruhi oleh intensitas perhatian dan persepsi terhadap objek. Dari definisi yang ada dapat disimpulkan bahwa knowledge adalah sesuatu yang didapatkan melalui pembelajaran dimana faktor mempengaruhi faktor dari dalam seperti motivasi dan faktor dari luar berupa informasi atau maklumat yang diketahui serta disadari oleh seseorang. (Adzima \& Sjahruddin, 2019)

\section{Konsep Dasar Zakat, Infaq dan Sadaqah (ZIS)}

"Para ulama secara terminologis mengemukakan pengertian zakat dengan redaksi yang agak berbeda, namun secara substansi memiliki pemahaman yang sama, yaitu bahwa zakat adalah bagian dari harta dengan persyaratan tertentu, yang Allah SWT mewajibkan kepada pemiliknya untuk diserahkan kepada pihak yang berhak menerimanya. Dengan persyaratan tertentu pula". (K Rahman, 2017)

Imam-imam mazhab seperti Malikiyah, Hanafiyah, Syafieciyah dan Hambali memiliki titik tekan yang sama dalam memaknai zakat. Malikiyah memaknai zakat sebagai mengeluarkan sebagaian harta tertentu ketika telah sampai nisab kepada mustahiq, jika telah sempurna kepemilikannya kecuali pada harta tambang dan hasil pertanian. Zakat bagi kelompok Hanafiyah adalah harta tertentu yang dikeluarkan menurut ketentuan syara' untuk memperoleh ridha Allah Swt.

Dalam al-Qur"an dapat dilihat dalam surat AlBaqarah: 195. Artinya: "Dan infakkanlah (hartamu) dijalan Allah, dan janganlah kamu jatuhkan (diri sendiri) ke dalam kebinasaan dengan tangan sendiri, dan berbuat baiklah. Sungguh, Allah menyukai orang-orang yang berbuat baik (Al-Baqarah: 195)".

Jika zakat ada nisabnya, infaq tidak mengenal nisab. Jika zakat harus diberikan pada mustahiq tertentu (8 asnaf), infaq boleh diberikan kepada siapapun juga, misalnya untuk kedua orang tua atau anak yatim dan sebagainya, dijelaskan dalam firman Allah surat AlBaqarah: 215.

Artinya : "Mereka bertanya kepadamu (Muhammad) tentang apa yang harus mereka infakkan. Katakanlah, 'Harta apa saja yang kamu infakkan, hendaknya diperuntukkan bagi kedua orang tua, kerabat, anak yatim, orang miskin, dan orang yang dalam perjalanan'. Dan kebaikan apa saja yang kamu kerjakan, maka sesungguhnya Allah Maha Mengetahui (AlBaqarah: 215)."

Sedangkan sadaqah adalah suatu pemberian yang diberikan oleh seorang muslim kepada orang lain secara spontan dan sukarela tanpa dibatasi waktu dan jumlah tertentu, suatu pemberian yang diberikan oleh seseorang sebagai suatu kebajikan yang mengharap ridha Allah SWT dan pahala semata.(Haris Nasution Absul, Nisa Khoirun, 2018)

\section{Zakat Melalui Amil Zakat}

Amil zakat adalah panitia atau orang-orang yang melakukan segala kegiatan yang berkaitan erat dengan zakat. Mereka bertugas mengumpulkan, menghitung, mencatat, menjaga dan membagikan harta zakat yang berhasil mereka himpun kepada orang-orang yang berhak menerimanya. (Yuniar, 2017)

\section{Bahasa Pemrograman}

Bahasa Pemrograman atau biasa disebut juga dengan bahasa komputer merupakan suatu himpunan dari aturan sintaks dan semantik yang dipakai untuk mendefinisikan program komputer yang berfungsi untuk mengolah data sesuai alur berpikir yang diinginkan oleh user.

\section{HTML 5}

HTML 5 adalah versi terbaru dari HTML (Hypertext Markup Languange) sebelumnya yaitu, HTML 4.01, XHTML 1.0, dan XHTML 1.1. HTML 5 dikembangkan dengan fitur-fitur baru yang dibutuhkan untuk pengembangan aplikasi web yang canggih.

2. PHP

PHP adalah bahasa pemrogramam interpreter yaitu proses penerjemahan baris kode sumber menjadi kode mesin yang dimengerti komputer secara langsung pada saat baris kode dijalankan. PHP disebut sebagai pemrograman server side programming, hal ini dikarenakan seluruh prosesnya dijalankan pada server. PHP adalah suatu bahasa dengan hak cipta terbuka atau yang juga dikenal dengan istilah Open Source, yaitu pengguna dapat mengembangkan kode-kode fungsi PHP sesuai dengan kebutuhan. Pemrograman PHP dapat di tulis dalam dua bentuk yaitu penulisan baris kode PHP pada file tunggal dan penulisan kode PHP pada halaman (embedded). Kedua penulisan tersebut tidak memiliki perbedaan, hanya menjadi kebiasaan gaya penulisan dari programmer.

3. Cascading Style Sheet (CSS)

Cascading Style Sheet (CSS) merupakan aturan untuk mengendalikan beberapa komponen dalam sebuah web sehingga akan lebih terstruktur dan seragam. Pada umumnya CSS dipakai untuk memformat tampilan halaman web yang dibuat dengan bahasa HTML dan XHTML. CSS dapat mengendalikan ukuran gambar, warna bagian tubuh pada teks, warna tabel, ukuran border, warna border, warna hyperlink, warna mouse over, spasi antar paragraf, spasi antar teks, margin kiri, kanan, atas, bawah, dan parameter 
lainnya. CSS adalah bahasa style sheet yang digunakan untuk mengatur tampilan dokumen.

4. API (Application Programming Interface)

API adalah seperangkat aturan tertentu atau algoritma tertentu yang dikodekan dengan spesifik dapat digunakan dan berkomunikasi oleh perangkat 21 lunak lainnya (Aplikasi). Berfungsi sebagai antarmuka antar program perangkat lunak yang berbeda dan memfasilitasi interaksi antar kedua aplikasi tersebut, mirip dengan cara antarmuka pengguna memfasilitasi interaksi antar antara manusia dan komputer dapat digunakan dan berkomunikasi oleh perangkat 21 lunak lainnya (Aplikasi). Berfungsi sebagai antarmuka antar program perangkat lunak yang berbeda dan memfasilitasi interaksi antar kedua aplikasi tersebut, mirip dengan cara antarmuka pengguna memfasilitasi interaksi antar antara manusia dan komputer

5. Jquery Mobile

Jquery telah lama menjadi JavaScriptlibrary yang populer untuk menciptakan wabsite interaktif yang kaya dan aplikasi web. Namun, karena ini dirncang terutama untuk browser, Jquery tidak memiliki banyak fitur yang khusus dirancang untuk membangun aplikasi web mobile. Jquery Mobile adalah proyek baru yang membahas kekurangan ini. Ini adalah framework yang dibangun diatas jQuery yang menyediakan berbagai elemen User-Interface dan fitur-fitur untuk digunakan dalam aplikasi mobile. Beberapa fitur kunci dan manfaat dari jquery mobile dan menunjukan beberapa contoh bagaimana framework baru ini dapat membantu membangun aplikasi mobile berkualitas dan dalam waktu singkat.

6. PhoneGap

PhoneGap adalah open source framework untuk membuat cross-platform native applications menggunakan teknologi web mulai dari HTML, CSS, dan JavaScript. Tipe dari aplikasi ini disebut sebagai hybrid application. PhoneGap diciptakan untuk mempermudah mobile development.

7. Eclipse

Eclipse adalah sebuah IDE (Integrated Development Environment) untuk mengembangkan perangkat lunak dan dapat dijalankan di semua platform (platform-independent)

8. Xampp adalah perangkat lunak bebas, yang mendukung banyak sistem operasi, merupakan kompilasi dari beberapa program.

Fungsinya adalah sebagai server yang berdiri sendiri (localhost), yang terdiri atas program apache HTTP server, MySQL database, dan penerjemah bahasa yang ditulis dengan bahasa pemrograman PHP dan Perl. Nama XAMPP merupakan singkatan dari $\mathrm{X}$ (empat sistem operasi apapun), Apache, MySQL, PHP dan Perl. Program ini tersedia dalam GNU General Public License dan bebas, merupakan web server yang mudah digunakan yang dapat melayani tampilan halaman yang dinamis.

9. Global Positioning System (GPS)

GPS (Global Positioning System) merupakan sebuah sistem satelit navigasi dan penentuan posisi dengan menggunakan satelit. GPS dapat memberikan informasi tentang posisi, kecepatan, dan waktu secara cepat, akurat, murah, dimana saja di bumi ini pada setiap saat tanpa tergantung cuaca. Pada dasarnya GPS terdiri atas tiga segmen utama, yaitu segmen angkasa (space segment) yang terdiri dari satelitsatelit GPS, segmen sistem kontrol (control system segment) yang terdiri dari stasiun-stasiun pengamat dan pengendali satelit, dan segmen pemakai (user segment) yang terdiri dari pemakai GPS termasuk alatalat penerima dan pengolah sinyal dan data GPS.

10.Basis Data

Database atau biasa disebut basis data merupakan kumpulan data yang saling berhubungan. Data tersebut biasanya terdapat dalam tabel-tabel yang saling berhubungan satu sama lain, dengan menggunakan field/kolom pada tiap tabel yang ada.

11. Model Pengembangan Perangkat Lunak

Dalam pengembangan sistem yang diusulkan, penulis menggunakan metode waterfall. Nama model ini sebenarnya adalah "Linear Sequential Model". Model ini sering disebut juga dengan "Classic Life Cycle" atau metode waterfall.

Metode waterfall sangat cocok digunakan dalam membangun sebuah sistem baru dengan cepat dan mudah. Metode ini sangat baik juga digunakan terutama dalam hal kelanjutan pengembangan sistem dengan dokumentasi yang lengkap (Riyandi, 2019).

HASIL DAN PEMBAHASAN

Tahapan Perancangan Sistem

Knowledge Management System Untuk BAZNAS Kabupaten Tangerang

Pemetaan SECI Model pada proses manajemen pengetahuan di BAZNAS Kabupaten Tangerang. Dalam penerapan atau implementasi sistem manajemen pengetahuan (knowledge management system) di BAZNAS Kabupaten Tangerang tidak hanya didukung oleh SDM yang berkualitas (memiliki informasi, pengalaman dan keahlian yang dibutuhkan) dan teknologi yang tepat, tapi berbagi budaya knowledge yang diterapkan. Berikut ini adalah pemetaan infrastruktur teknologi ke dalam proses sistem manajemen pengetahuan: 
Tabel 1. SECI Sistem Manajemen Pengetahuan BAZNAS Kabupaten Tangerang

\begin{tabular}{|l|l|}
\hline Socialization Tacit- Tacit & Externalization Tacit - Explicit
\end{tabular}

1. Bertatap muka untuk komunikasi, dalam hal ini para pegawai BAZNAS melakukan sosialisasi atau menggunakan forum diskusi, pesan untuk langsung berinteraksi dengan masyarakat.

2. Dalam konversi tacit ke tacit, terdapat menu diskusi dan pesan, agar setiap individu baik dari masyarakat maupun BAZNAS dapat saling berinteraksi, mereka dapat berbagi tacit knowledge mereka

Combin Cation Explicit - Explicit

1. Pengetahuan yang telah terdokumentasikan oleh pegawai BAZNAS kemudian dapat menjadi rujukan dalam pengembangan pengetahuan baru yang akan dibuat.

2. Dalam konversi explicit ke explicit, terdapat fitur berita, artikel, dan dokumen, yang dapat dipergunakan kembali oleh pegawai dalam pembuatan pengetahuan explicit yang baru.

1. Pengetahuan tentang ZIS dan BAZNAS yang dimiliki pegawai berdasarkan tacit knowledge yang ada, di dokumentasikan yang kemudian dipublikasikan kepada masyarakat.

2. Dalam konversi tacit ke explicit, terdapat fitur berita, artikel, dan dokumen, yang dimana semuanya dibuat berdasarkan pengetahuan tacit pegawai BAZNAS yang kemudian diolah dan didokumentasikan.

\section{Internalization Explicit - Tacit}

1. Pengetahuan tentang ZIS dan BAZNAS yang telah terdokumentasikan kemudian dibaca oleh masyarakat.

2. Dalam konversi explicit ke tacit, terdapat fitur berita, artikel, dan dokumen, agar setiap masyarakat dapat membaca, supaya menambah pengetahuan dan nilai - nilai keagamaan dalam diri mereka yang kemudian di amalkan dalam kehidupan sehari -harinya.

\section{Analisis Sistem Usulan}

1. SDM memasukkan dan mengelola pengetahuan dari berbagai sumber dalam sistem berupa: a) Memasukkan data pengetahuan; b) Meng upload file pengetahuan berupa file presentasi, dan laporan laporan yang ada pada BAZNAS Kabupaten Tangerang;

2. Menyimpan file pengetahuan yang sudah terkumpul dari berbagai sumber;

3. Wakil ketua melakukan validasi dan pengelolaan pengetahuan dari SDM; b) Mengubah data pengetahuan jika terjadi kesalahan.

4. Masyarakat mengecek ketersediaan pengetahuan.

5. Apabila pengetahuan yang dicari tersedia berupa tulisan, foto, file presentasi dan lain-lain sesuai dengan kebutuhan masyarakat;

6. Admin memonitoring file dan mengolah data user.

\section{Kebutuhan Fungsional}

Tabel 2. Kebutuhan Fungsional Sistem

\begin{tabular}{|c|c|c|}
\hline ID & FUNGSI & KETERANGAN \\
\hline A001 & Registrasi & Pengunjung dapat mengisi data diri untuk mendaftar sebagai user \\
\hline A002 & Login & $\begin{array}{l}\text { Pengguna dapat memasukkan nama username dan password untuk masuk ke dalam } \\
\text { sistem }\end{array}$ \\
\hline A003 & Tambah Data User & Sistem dapat melakukan input data user, edit data user, dan melihat data user. \\
\hline A004 & Tambah Data Pegawai & $\begin{array}{l}\text { Sistem dapat melakukan input data pegawai, edit data pegawai, mencari dan melihat } \\
\text { data pegawai. }\end{array}$ \\
\hline A005 & Melihat data pengunjung & Sistem dapat menampilkan data pengunjung \\
\hline A006 & Tambah Data Pengetahuan & $\begin{array}{l}\text { Sistem dapat melakukan input data pengetahuan, edit data pengetahuan, mencari dan } \\
\text { melihat data pengetahuan. Data pengetahuan yang diinput adalah: } \\
\text { 1. Data Artikel; } \\
\text { 2. Data Berita; } \\
\text { 3. Data Dokumen. }\end{array}$ \\
\hline A007 & Edit Data Artikel & Sistem dapat melakukan edit data artikel, mencari dan melihat data artikel. \\
\hline A008 & Edit Data Berita & Sistem dapat melakukan edit data berita, mencari dan melihat data berita. \\
\hline A009 & Edit Data Dokumen & Sistem dapat melakukan edit data dokumen, mencari dan melihat data dokumen. \\
\hline A010 & Validasi Diskusi & Sistem dapat memvalidasi data diskusi \\
\hline A011 & Validasi Artikel & Sistem dapat memvalidasi data artikel \\
\hline A012 & Validasi Berita & Sistem dapat memvalidasi data berita \\
\hline A013 & Validasi Dokumen & Sistem dapat memvalidasi data dokumen \\
\hline $\mathrm{A} 014$ & Melihat Data Artikel & Sistem dapat menampilkan data artikel untuk pengunjung \\
\hline
\end{tabular}

\section{Kebutuhan Non-fungsional}

a. Sistem hanya dapat digunakan di operating sistem android

b. Sistem hanya menyediakan dalam satu bahasa saj.

c. BAZNAS Kabupaten Tangerang harus mempunyai printer untuk mencetak laporan. 
Imron, Nurul Azizah, M. Sinta Nurhayati dan Bambang Wijonarko, Perancangan Aplikasi Mobile Zakat dan Infaq Berbasis Android Pada Baznas Kabupaten Tangerang

\section{Rancangan Diagram Use Case}

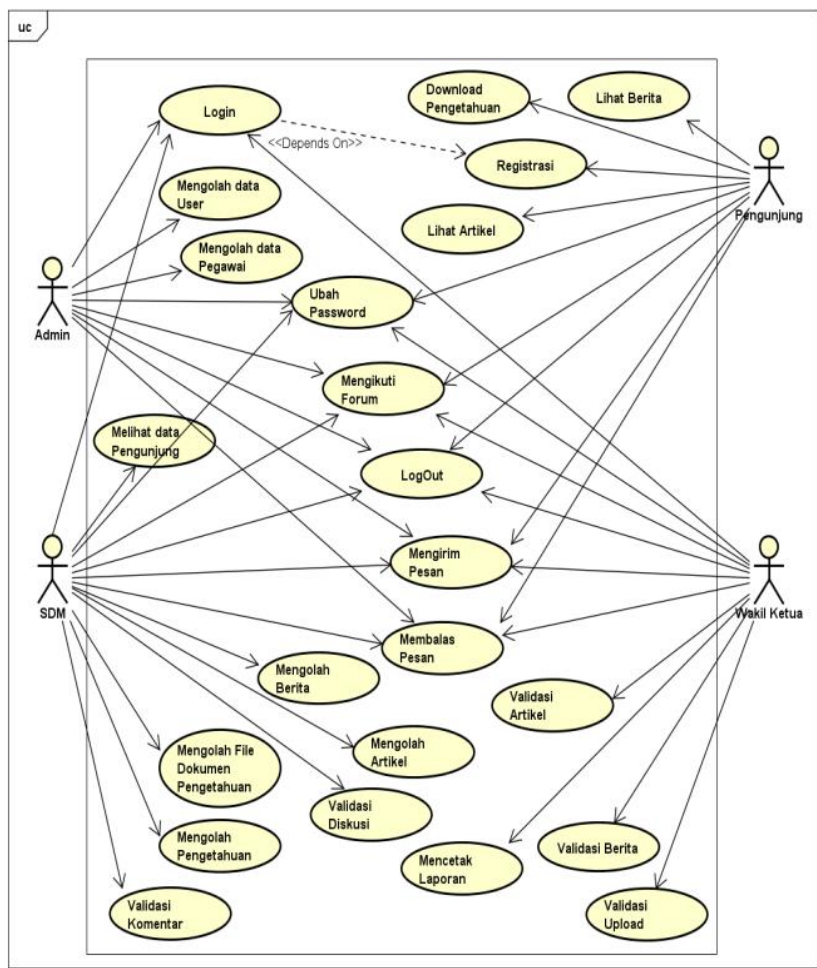

Gambar 1. Use Case Diagram

\section{Activity Diagram Login}

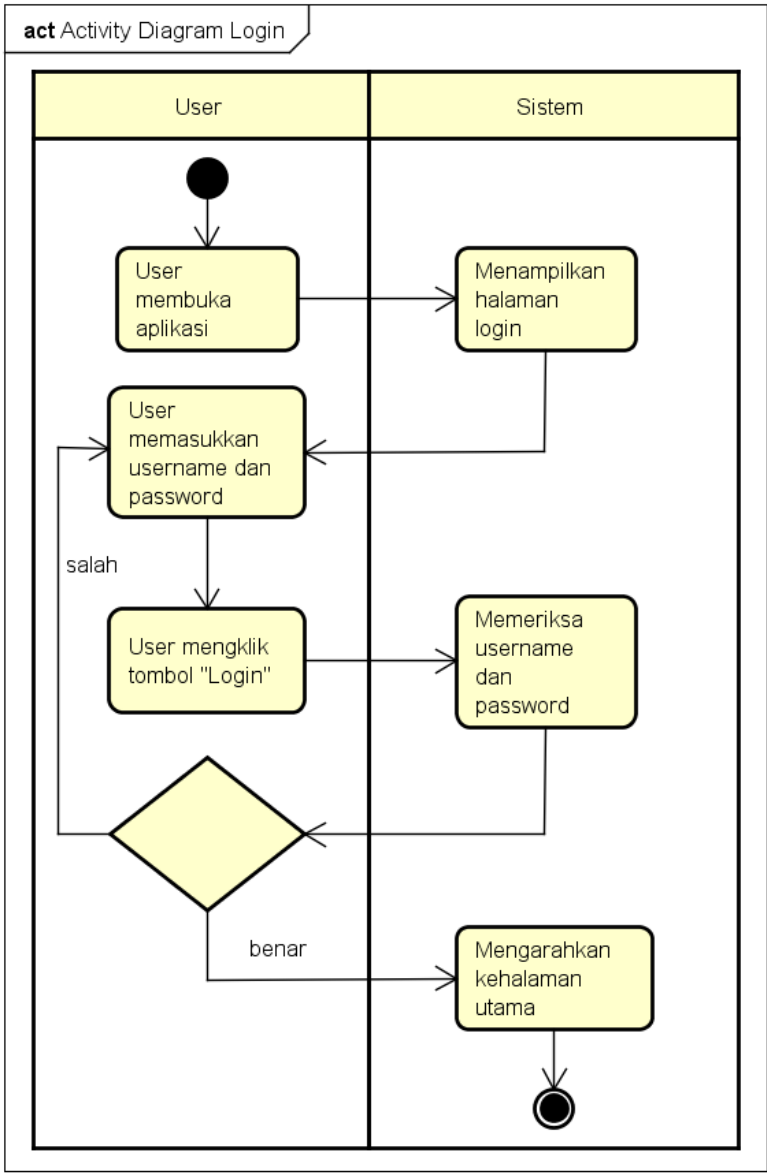

Gambar 2. Activity Diagram Login

\section{Activity Diagram Mengolah Data User}

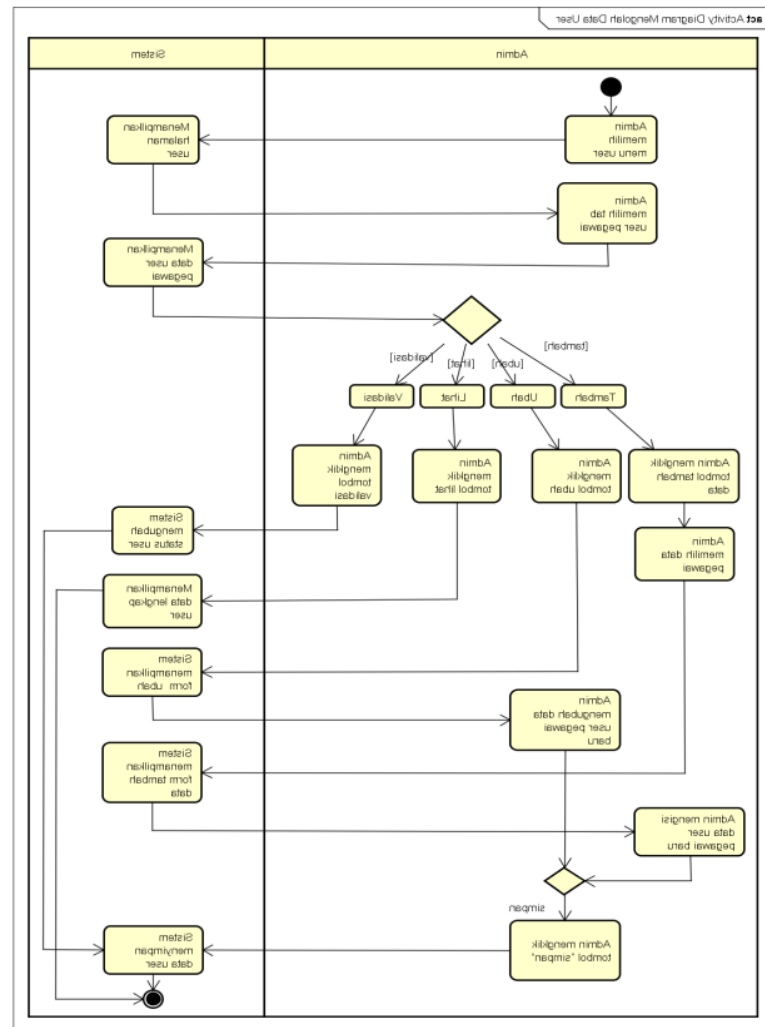

Gambar 3. Activity Diagram Mengolah Data User

Pada gambar diatas menggambarkan aktifitas admin ketika mengolah data user. Dalam mengolah data user ini terdapat 4 aktifitas, yaitu menambah, mengubah, melihat dan memvalidasi. Salah satu aktifitas adalah menambah data, admin pertama memilih tab user pegawai, mengklik tambah data, memilih data pegawai, mengisi data user pegawai baru dan mengklik tombol simpan untuk kemudian disimpan dalam database.

\section{Rancangan Prototype \\ Halaman Login}

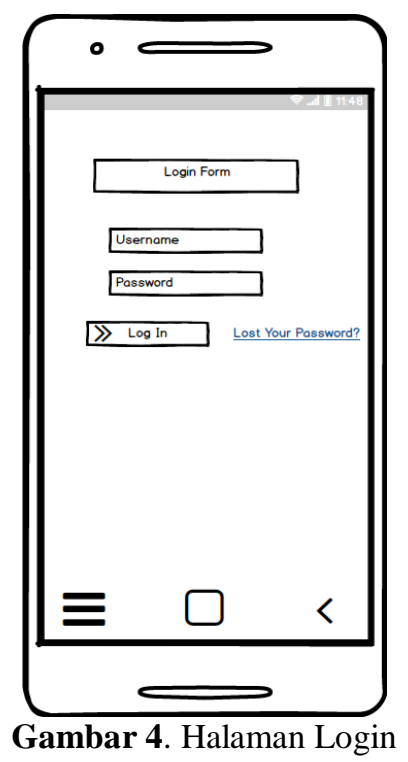


Imron, Nurul Azizah, M. Sinta Nurhayati dan Bambang Wijonarko, Perancangan Aplikasi Mobile Zakat dan Infaq Berbasis Android Pada Baznas Kabupaten Tangerang

Halaman Home Admin

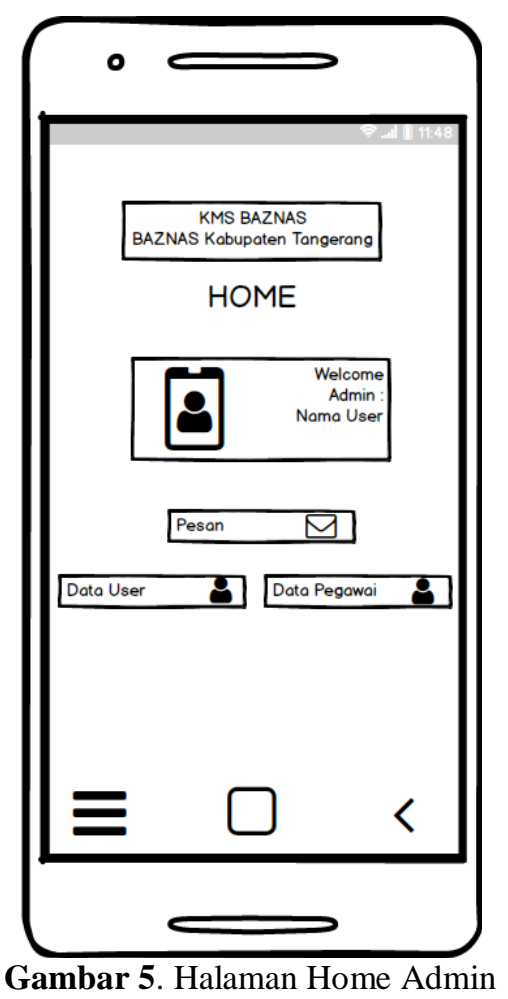

\section{Halaman Home SDM}

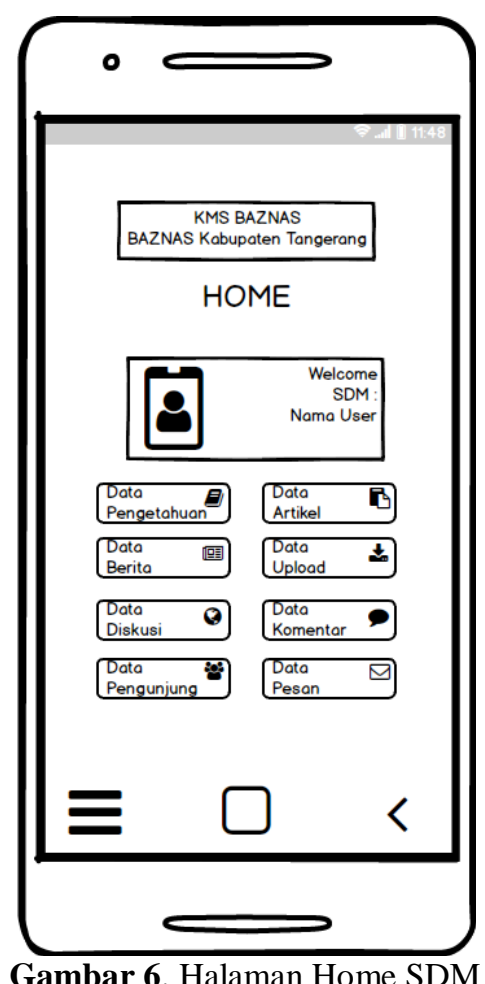

Halaman Data Komentar

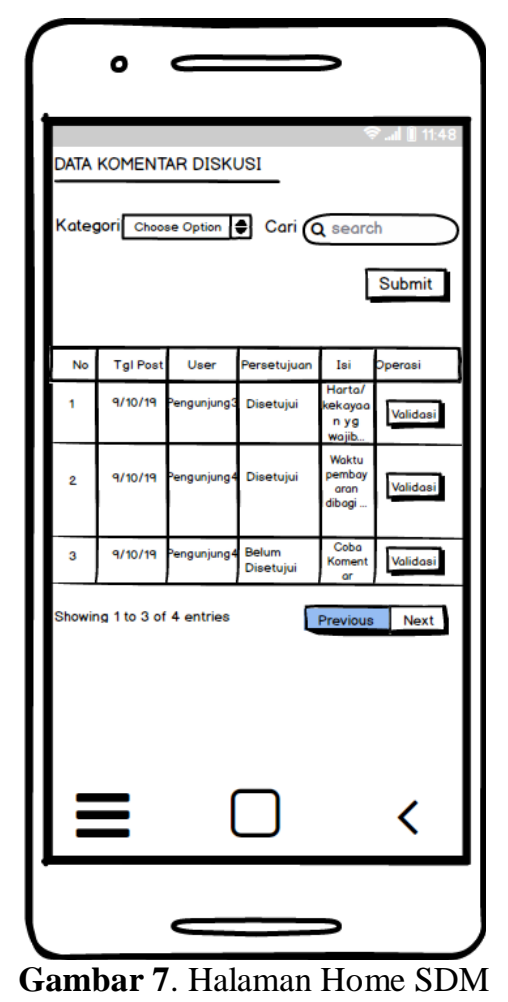

Entity Relationship Diagram (ERD)

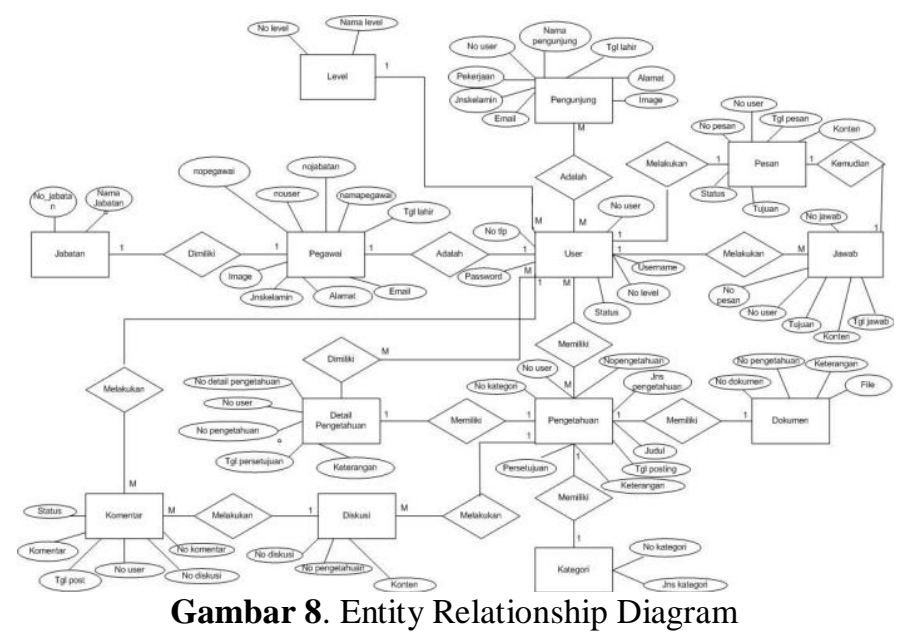

Sequence Diagram Login

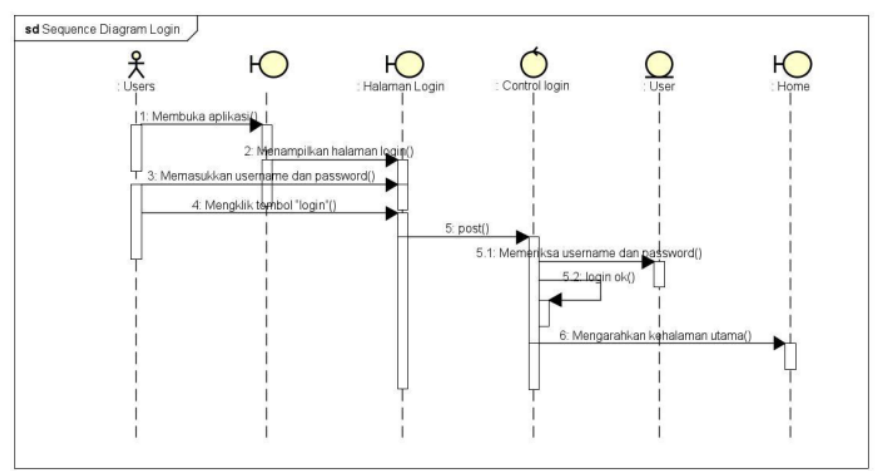

Gambar 9. Sequence Diagram Login 


\section{Deployment Diagram}

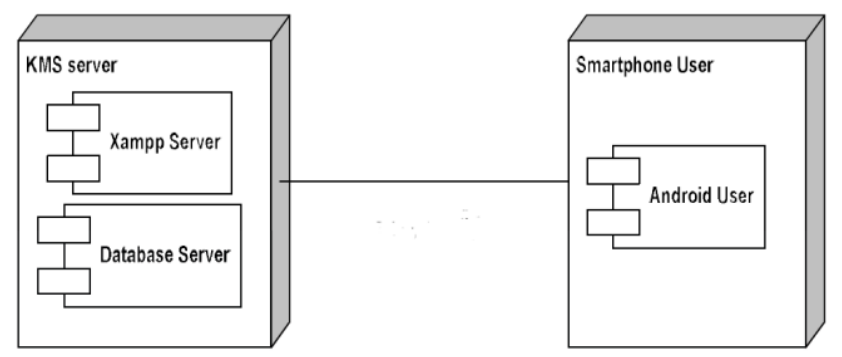

Gambar 10. Entity Relationship Diagram

\section{Component Diagram}

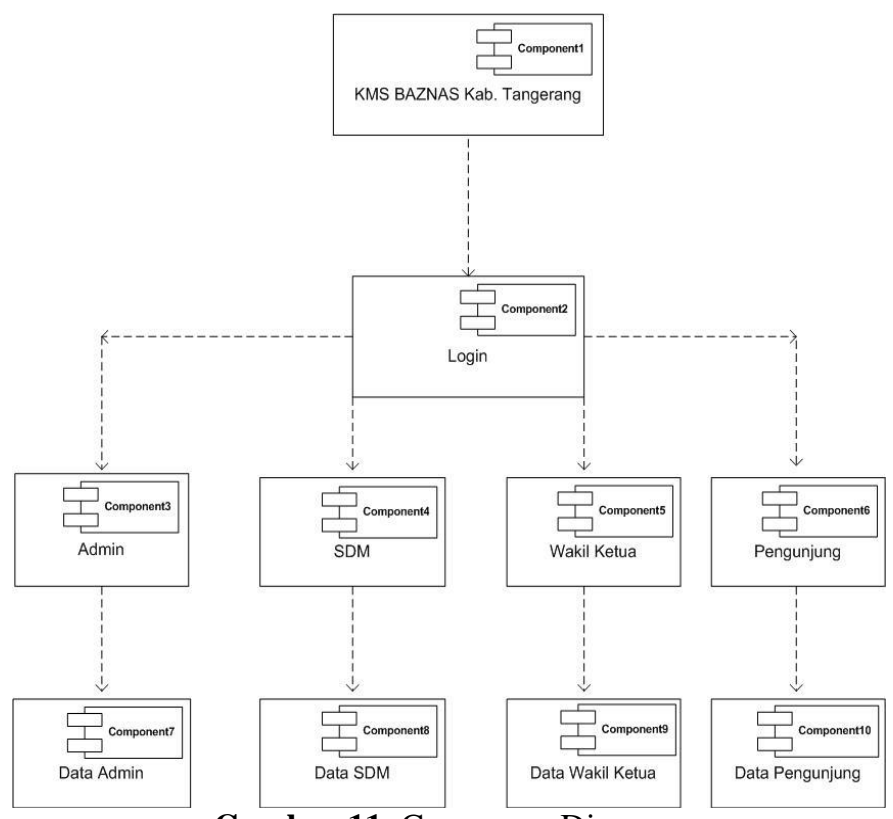

Gambar 11. Componen Diagram

\section{SIMPULAN}

Berdasarkan uraian dan pembahasan, peneliti sudah mengembangkan sebuah sistem manajemen pengetahuan pada BAZNAS Kabupaten Tangerang yang menghasilkan sebuah sistem yang dapat menangani dan mengurangi masalah yang terjadi pada BAZNAS Kab. Tangerang, yaitu sebagai berikut:

1. Sistem dapat dikembangkan dengan mengintegrasikan knowledge management system ini dengan sistem yang terkait pencatatan penerimaan dan pendistribusian zakat

2. BAZNAS Kabupaten Tangerang harus melakukan sosialisasi untuk knowledge management sytem ini, agar masyarakat mengetahui akan sistem ini. Untuk Pemerintah Kabupaten Tangerang, hasil penelitian ini dapat dijadikan acuan agar nantinya dapat mengembangkan sistem manajemen pengetahuan yang membahas tentang ke islaman, yang dimana nantinya dapat membantu Pemerintah dalam mewujudkan visinya yaitu "Mewujudkan Masyarakat Kabupaten Tangerang yang Cerdas, Religius, Makmur, dan Berwawasan Lingkungan"
3. Pengumpulan, penyimpanan, dan berbagi pengetahuan akan BAZNAS dan ZIS kepada masyarakat dengan adanya artikel, berita, dokumen pengetahuan, dan forum diskusi, dapat meningkatkan kepercayaan kepada BAZNAS Kabupaten Tangerang dan juga menumbuhkan nilai-nilai keagamaan dalam diri masyarakat.

\section{DAFTAR PUSTAKA}

Adzima, F., \& Sjahruddin, H. (2019). Pengaruh Knowledge Management Terhadap Kinerja Pengawai. Jurnal Organisasi Dan Manajemen, l(1), 58-56.

https://doi.org/10.5281/zenodo.3459964

Alinto, Yulianti, \& Ricoida, D. I. (2014). Perancangan Knowledge Management System Layanan Perbaikan Motor Pada Pt Xyz. http://eprints.mdp.ac.id/990/

Haris Nasution, A., Nisa, K., Zakariah, M., Muhammad Askari Zakariah, D., Ilmu Al-Quran dan Tafsir, D., Al-Mawaddah Warrahmah Kolaka, S., Prodi Ekonomi Syariah, M., Pendidikan Agama Islam, D., \& Ekonomi Syariah, D. (2018). Sekolah Tinggi Agama Islam Al-Mawaddah Warrahmah Kolaka. Jurnal Ekonomi Bisnis Syariah, 1(1), 2237. https://doi.org/10.5281/zenodo.1148842

Hidayah, D. (2017). Simulasi Aplikasi Kalkulator Resistor Berbasis Android. Jurnal Politeknik Negeri Sriwijaya, 5(September 2008), 7-29. http://eprints.polsri.ac.id/4490/3/File 3.pdf

K Rahman. (2017). Zakat profesi dan pengembangan pendidikan islam. Jurnal Ar Risalah, Vol.XIV No. 2 Oktober 2014. IAI Ibrahimy.ac.id. http://ejournal.iaiibrahimy.ac.id/index.php/arrisala h/article/view/116/130

Keputusan Presiden RI No. 8 Tahun 2001. Badan Amil Zakat Nasional. https://pid.baznas.go.id/download/008_NOMOR8 TAHUN2001_FC.pdf

Lusa, J. S., \& Haris. (2016). Model Knowledge Management System Dengan Teknologi Cloud Computing. Knowledge Management, 1-7.

Riyandi, A. (2019). Sistem Informasi Ketersediaan Ruangan Rumah Sakit Terintegrasi Aplicare BPJS Kesehatan. XXI(1), https://doi.org/10.31294/p.v20i2

Selpi Hasanah. (2018). Aplikasi Perancangan Booth Jenius Bank BTPN Berbasis Mobile. 1-4.

Siregar, Mukmin, Permana, I., Sistem, J., Fakultas, I., Dan, S., Uin, T., Riau, S., Soebrantas, J. H., \& Pekanbaru-Riau, P. (2016). Rancang Bangun Aplikasi Berbasis Mobile Untuk Navigasi Ke Alamat Pelanggan Tv Berbayar (Studi Kasus: Indovision Cabang Pekanbaru) 1. Jurnal Rekayasa Dan Manajemen Sistem Informasi, 2(1), 82-94. www.hostinger.co.id 
Imron, Nurul Azizah, M. Sinta Nurhayati dan Bambang Wijonarko, Perancangan Aplikasi Mobile Zakat dan Infaq Berbasis Android Pada Baznas Kabupaten Tangerang

Undang-undang RepublikIndonesia No. 23 Tahun 2011.

Pengelolaan

Zakat.

https://pid.baznas.go.id/download/001_Undang-

Undang_Nomor_23_Tahun_2011_Tentang_Peng

elolaan_Zakat_FC.pdf

Yuniar, K. (2017). Optimalisasi Pengelolaan Zakat Dan Efektifitas Amil Zakat Terhadap Peningkatan Perolehan Zakat, Infak, Sedekah Di Baznas Tulungagung. 17-46. Ta'allum: Jurnal Pendidikan Islam. IAIN Tulungagung. https://doi.org/10.21274/taalum.2020.8.2.286-308 